Merck, Novartis, Pfizer, UCB, Grant/research support from: Abbott, Bristol Myers Squibb, Celgene, Celltrion, Chugai, Johnson \& Johnson, MSD, Novartis, Pfizer, Roche, UCB Pharma, Grant/research support from: AbbVie, BMS, Celgene, Chugai, Merck, Novartis, Pfizer, UCB, Grant/research support from: Abbvie (Abbott), Amgen, Baxter, Biogen, BMS, Boehringer Celgene, Celltrion, Centocor, Chugai, Hexal, Janssen, Lilly, Medac, MSD (Schering-Plough), Mylan, Mundipharma, Novartis, Pfizer (Wyeth, Hospira), Roche, Sanofi-Aventis and UCB, Consultant for: Abbvie (Abbott), Amgen, Baxter, Biogen, BMS, Boehringer, Celgene, Celltrion, Centocor, Chugai, Hexal, Janssen, Lilly, Medac, MSD (Schering-Plough), Mylan, Mundipharma, Novartis, Pfizer (Wyeth, Hospira), Roche, Sanofi-Aventis and UCB, Consultant for: AbbVie, BMS, Celgene, Chugai, Merck, Novartis, Pfizer, UCB, Consultant for: Abbott, Bristol Myers Squibb, Celgene, Celltrion, Chugai, Johnson \& Johnson, MSD, Novartis, Pfizer, Roche, UCB Pharma, Speakers bureau: AbbVie, BMS, Celgene, Chugai, Merck, Novartis, Pfizer, UCB, Speakers bureau: Abbvie (Abbott), Amgen, Baxter, Biogen, BMS, Boehringer, Celgene, Celltrion, Centocor, Chugai, Hexal, Janssen, Lilly, Medac, MSD (Schering-Plough), Mylan, Mundipharma, Novartis, Pfizer (Wyeth, Hospira), Roche, Sanofi-Aventis and UCB, Speakers bureau: AbbVie, BMS, Celgene, Chugai, Merck, Novartis, Pfizer, UCB DOI: 10.1136/annrheumdis-2019-eular.5072

\section{SAT0317 INCIDENCE OF EXTRA-ARTICULAR MANIFESTATIONS IN ANKYLOSING SPONDYLITIS, PSORIATIC ARTHRITIS AND UNDIFFERENTIATED SPONDYLOARTHRITIS - RESULTS FROM A NATIONAL REGISTER-BASED COHORT STUDY}

Karin Bengtsson ${ }^{1}$, Helena Forsblad-D'elia ${ }^{1,2}$, Eva Klingberg ${ }^{1}$, Ulf Lindström ${ }^{1}$, Mats Dehlin ${ }^{1}$, Sofia Exarchou ${ }^{3}$, Anna Deminger ${ }^{1}$, Johan Askling ${ }^{4}$, Lennart T.

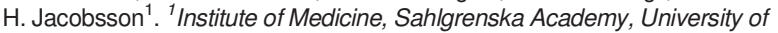
Gothenburg, Department of Rheumatology and Inflammation Research, Göteborg, Sweden; ${ }^{2}$ Umeå University, Department of Public Health and Clinical Medicine, Rheumatology, Umeå, Sweden; ${ }^{3}$ Lund University, Department of Clinical Sciences, Section of Rheumatology, Malmö, Sweden; ${ }^{4}$ Karolinska Institutet, Department of Medicine Solna, Clinical Epidemiology Unit and Rheumatology Unit, Stockholm, Sweden

Background: Spondyloarthritis (SpA), including ankylosing spondylitis (AS), psoriatic arthritis (PsA) and undifferentiated SpA (USpA), are all to varying degrees associated with extra-articular manifestations (EAMs).

Objectives: To estimate incidence rates (IRs) for EAMs (anterior uveitis, inflammatory bowel disease (IBD) and psoriasis) in patients with AS, PsA and $\mathrm{USpA}$, respectively.

Methods: In this nationwide cohort study, three separate cohorts of patients aged 18 to 69 years with AS ( $n=8517,68 \%$ men, mean age 47 \pm 13 years), PsA ( $n=22667,46 \%$ men, mean age $49 \pm 12$ years) and uSpA ( $n=10245,44 \%$ men, mean age $42 \pm 13$ years) were identified 2001 2015 in the Swedish National Patient Register (NPR). The follow-up began 1 January 2006, or six month after the date of the first SpA

Table 1.

\begin{tabular}{|c|c|c|c|c|c|c|}
\hline & \multicolumn{2}{|r|}{ AS } & \multicolumn{2}{|c|}{ PsA } & \multicolumn{2}{|c|}{ uSpA } \\
\hline & $\begin{array}{l}\text { Prior } \\
\text { EAM } \\
\mathrm{n}(\%)\end{array}$ & $\begin{array}{c}\text { IRs } \\
(95 \% \mathrm{Cl})\end{array}$ & $\begin{array}{l}\text { Prior } \\
\text { EAM } \\
\mathrm{n}(\%)\end{array}$ & $\begin{array}{c}\text { IRs } \\
(95 \% \mathrm{Cl})\end{array}$ & $\begin{array}{l}\text { Prior } \\
\text { EAM } \\
\mathrm{n}(\%)\end{array}$ & $\begin{array}{c}\text { IRs } \\
(95 \% \mathrm{Cl})\end{array}$ \\
\hline \multicolumn{7}{|c|}{$\begin{array}{l}\text { ANTERIOR } \\
\text { UVEITIS }\end{array}$} \\
\hline All & $\begin{array}{l}1852 \\
(22)\end{array}$ & $\begin{array}{c}14.4(13.2- \\
15.5)\end{array}$ & $\begin{array}{c}356 \\
(1.6)\end{array}$ & $\begin{array}{c}1.7(1.5- \\
1.9)\end{array}$ & $\begin{array}{l}1498 \\
(15)\end{array}$ & $\begin{array}{c}7.7(6.9- \\
8.5)\end{array}$ \\
\hline Men & $\begin{array}{l}1315 \\
(23)\end{array}$ & $\begin{array}{c}15.8(14.3- \\
17.3)\end{array}$ & $\begin{array}{l}177 \\
(1.7)\end{array}$ & $\begin{array}{l}1.7(1.4- \\
2.0)\end{array}$ & $771(17)$ & $\begin{array}{c}10.1(8.8- \\
11.5)\end{array}$ \\
\hline $\begin{array}{l}\text { Women } \\
\text { IBD }\end{array}$ & $537(20)$ & $\begin{array}{c}11.2(9.4- \\
13.1)\end{array}$ & $\begin{array}{l}179 \\
(1.5)\end{array}$ & $\begin{array}{l}1.8(1.5- \\
2.1)\end{array}$ & 727 (13) & $\begin{array}{c}6.0(5.1- \\
6.9)\end{array}$ \\
\hline All & $\begin{array}{l}615 \\
(7.2)\end{array}$ & $2.8(2.4-3.3)$ & $\begin{array}{c}504 \\
(2.2)\end{array}$ & $\begin{array}{c}1.1(0.9- \\
1.3)\end{array}$ & $\begin{array}{l}632 \\
(6.2)\end{array}$ & $\begin{array}{l}2.5(2.1- \\
2.9)\end{array}$ \\
\hline Men & $\begin{array}{l}403 \\
(7.0)\end{array}$ & $2.6(2.0-3.1)$ & $\begin{array}{c}192 \\
(1.8)\end{array}$ & $\begin{array}{c}1.0(0.8- \\
1.2)\end{array}$ & $\begin{array}{l}268 \\
(5.9)\end{array}$ & $\begin{array}{c}2.6(2.0- \\
3.2)\end{array}$ \\
\hline Women & $\begin{array}{l}212 \\
(7.7)\end{array}$ & $3.4(2.5-4.3)$ & $\begin{array}{l}312 \\
(2.6)\end{array}$ & $\begin{array}{c}1.2(1.0- \\
1.4)\end{array}$ & $\begin{array}{l}364 \\
(6.4)\end{array}$ & $\begin{array}{l}2.4(1.8- \\
2.9)\end{array}$ \\
\hline $\begin{array}{l}\text { PSORIAS } \\
\text { All }\end{array}$ & 264 & $5.6(5.0-6.3)$ & $N A$ & $N A$ & 405 & $7.7(7.0-$ \\
\hline Men & $\begin{array}{l}(\mathbf{3 . 1}) \\
171 \\
(3.0)\end{array}$ & $5.4(4.7-6.2)$ & $N A$ & $N A$ & $\begin{array}{l}(4.0) \\
199 \\
(4.4)\end{array}$ & $\begin{array}{l}8.4) \\
6.9(5.9- \\
8.0)\end{array}$ \\
\hline Women & $93(3.4)$ & $6.1(4.9-7.3)$ & $N A$ & $N A$ & $\begin{array}{l}206 \\
(3.6)\end{array}$ & $\begin{array}{c}8.3(7.3- \\
9.3)\end{array}$ \\
\hline
\end{tabular}

The IRs are presented as number of EAMs per 1000 person-years at risk. NA, not applicable. diagnosis thereafter in previously undiagnosed cases, and ended at the first date of EAM, death, emigration or 31 December 2016, respectively. Both the SpA diagnoses and EAMs were identified according to specified ICD codes. Number of outcomes, person-years at risk and IRs with $95 \%$ $\mathrm{Cl}$ were calculated for each EAM and stratified by sex and age-intervals. Patients with a prior EAM in NPR before start of follow-up were excluded from that specific analysis.

Results: The IRs for each EAM are presented in Table 1. The overall highest IRs were noted for anterior uveitis in patients with AS (14.4 (13.2-15.5) per 1000 person-years at risk). Patients with PsA had considerably lower IRs for anterior uveitis (1.7 (1.5-1.9) per 1000 person-years at risk) and slightly lower IRs for IBD than patients with AS and USpA The IRs for anterior uveitis were significantly higher in men than in women in both AS and USpA.

Conclusion: IRs for EAMs clearly differed between the SpA subtypes, and especially for anterior uveitis where the IRs were by far highest in patients with AS and USpA compared to patients with PsA.

Disclosure of Interests: Karin Bengtsson: None declared, Helena Forsblad-d'Elia Grant/research support from: Unrestricted grants from Novartis outside the submitted work, Consultant for: Advisory board fees from Sandoz, Novartis and Abbvie, Speakers bureau: Lecturing fees from Novartis, Eva Klingberg Grant/research support from: Unrestricted grant from Roche, Consultant for: Novartis, Speakers bureau: Speakers fee from Lilly, Ulf Lindström: None declared, Mats Dehlin: None declared, Sofia Exarchou: None declared, Anna Deminger: None declared, Johan Askling Grant/research support from: Karolinska Institutet (JA) has or has had research agreements with the following pharmaceutical companies, mainly in the context of the ATRIS national safety monitoring programme for rheumatology biologicals: Abbvie, BMS, MSD, Eli Lilly, Pfizer, Roche, Samsung Bioepis, and UCB., Consultant for: Karolinska Institutet has received remuneration for JA participating in ad boards arranged by Lilly, Novartis, and Pfizer., Lennart T.H. Jacobsson Consultant for: LJ has received lecture and consulting fees from Pfizer, Abbvie, Novartis, Eli-Lily and Janssen

DOI:10.1136/annrheumdis-2019-eular.4422

\section{SAT0318 PREVALENCE AND PREDICTORS OF DEPRESSION AMONG PATIENTS WITH ANKYLOSING SPONDYLITIS AND PSORIATIC ARTHRITIS IN A CANADIAN REAL WORLD OBSERVATIONAL COHORT: RESULTS FROM THE COMPLETE STUDIES}

Louis Bessette $^{1}$, Majed Khraishi ${ }^{2}$, Viktoria Pavlova ${ }^{3}$, Jacqueline Stewart ${ }^{4}$, Valencia P. Remple ${ }^{5}$. 'Laval University, Centre Hospitalier de l'Université Laval, Quebec, Canada; ${ }^{2}$ Memorial University of Newfoundland, St. John's, Canada; ${ }^{3}$ McMaster University, Hamilton, Canada; ${ }^{4}$ University of British Columbia, Penticton, Canada ${ }^{5}$ AbbVie Corporation, Montreal, Canada

Background: Ankylosing pondylitis (AS) and psoriatic arthritis (PsA) are chronic inflammatory diseases known to cause physical, emotional, social and psychological impairment. However, few data are available on comorbidities such as depression and the factors associated with depression.

Objectives: To evaluate the prevalence of depression and to identify sociodemographic and disease-related factors associated with depression among PsA and AS patients.

Methods: Patients eligible for the COMPLETE studies are anti-TNFo naïve adults with active AS or PsA requiring change in their treatment regimen. In this analysis, patients enrolled between Jul/2011 - Nov/2017, treated with adalimumab or non-biologic DMARDs were included. Depression was defined as Beck's Depression Inventory (BDI) $\geq 20$ and/or patients treated with an antidepressant/anxiolytic at baseline (before treatment modification). Associated symptoms of depression were assessed with the BDI considering\% of patients with a score of 2 or 3 (moderate to severe symptoms). Univariate and multivariate logistic regression were used to identify sociodemographic and disease-related predictors associated with depression at baseline. In addition, the correlation of the BD score and the following parameters at baseline was assessed with the Pearson coefficient (r): age, disease duration, PsA disease specific parameters (28-tender [TJC] and swollen joint count [SJC], patient global assessment [PtGA], physician global assessment [MDGA]), and AS disease specific parameters (BASDAI, BASFI, morning stiffness, and number of extra-articular manifestations [EAMs]).

Results: A total of 492 AS and 333 PsA patients were included. Mean (SD) age was 42.7 (13.2) and 51.5 (12.2) years for AS and PsA, respectively, and disease duration was 5.4 (9.1) and 14.7 (13.7) years. The prevalence of baseline depression was $24.6 \%$ for AS and $25.5 \%$ for PsA. The most commonly reported symptoms of associated with depression, were loss of energy $(33.2 \%$ and $26.2 \%)$, changes in sleeping 
pattern $(41.3 \%$ and $34.9 \%$ ), fatigue $(35.3 \%$ and $28.6 \%)$, and loss of interest in sex $(21.7 \%$ and $21.9 \%)$, for AS and PsA, respectively.

In univariate analysis (Table 1), female gender $(\mathrm{OR}=1.73)$, unemployment due to disability $(O R=3.06)$ or other reasons $(O R=2.38)$, increased BASDAI $(O R=1.40)$, increased BASFI $(O R=1.33)$, and increased morning stiffness $(O R=1.01)$ were significantly associated [all $P<0.001$ except gender $(\mathrm{P}=0.009)$ ] with baseline depression among AS patients. For PsA, significantly associated parameters included female sex $(O R=2.35 ; P=0.001)$, unemployment due to disability $(\mathrm{OR}=3.57 ; \mathrm{P}<0.001)$, increased TJC $(\mathrm{OR}=1.05 ; \mathrm{P}=0.009)$, increased $\mathrm{PtGA} \quad(\mathrm{OR}=1.03 ; \mathrm{P}<0.001)$ and increased morning stiffness $(O R=1.01 ; P=0.010)$. Weak correlations $(P<0.05)$ were observed between the BDI score and BASFI ( $r=0.425)$, BASDAI $(r=0.375)$, morning stiffness $(r=0.285)$, and number of EAMs $(r=0.114)$ for $A S$; and TJC ( $r=0.155)$, MDGA ( $r=0.132)$, and PtGA $(r=0.451)$ for PsA. In multivariate regression analysis for $A S$, higher $B A S F I \quad(O R=1.32$; $\mathrm{P}<0.001)$, female sex $(O R=1.89 ; \mathrm{P}=0.007)$ and being unemployed due to other reasons $(O R=1.91 ; P=0.017)$; and, for $P s A$, lower baseline disease duration $(\mathrm{OR}=0.97 ; \mathrm{P}=0.018)$, and higher $\mathrm{PtGA}(\mathrm{OR}=1.04 ; \mathrm{P}<0.001)$ were identified as significant independent predictors of baseline depression. Conclusion: Depression in AS and PsA patients was common in this real-world cohort. Female sex, unemployment, and higher disease activity for AS, and shorter disease duration along with higher PtGA for PsA were significant independent predictors of depression.

Disclosure of Interests: Louis Bessette Grant/research support from: Amgen, BMS, Janssen, Roche, UCB, AbbVie, Pfizer, Merck, Celgene, Sanofi, Lilly, Novartis, Consultant for: Amgen, BMS, Janssen, Roche, UCB, AbbVie, Pfizer, Merck, Celgene, Sanofi, Lilly, Novartis, Speakers bureau: Amgen, BMS, Janssen, Roche, UCB, AbbVie, Pfizer, Merck, Celgene, Sanofi, Lilly, Novartis, Majed Khraishi Consultant for: AbbVie, Speakers bureau: AbbVie, Viktoria Pavlova Grant/research support from: UCB, Consultant for: Amgen, Abbvie, BMS, Janssen, Lilly, Merk, Novartis, Roche, UCB, Pfizer, Speakers bureau: Amgen, Abbvie, BMS, Janssen, Lilly, Merk, Novartis, Roche, UCB, Pfizer, Jacqueline Stewart Consultant for: Pfizer, Abbvie, Amgen, Celgene, Roche, Novartis, Merck, Valencia P. Remple Shareholder of: AbbVie, Employee of: AbbVie

DOI: 10.1136/annrheumdis-2019-eular.5693

\section{SAT0319 OBESITY AND ASSOCIATED FACTORS IN NORWEGIAN AXIAL SPONDYLOARTHRITIS PATIENTS. RESULTS FROM THE EUROPEAN MAP OF AXIAL SPONDYLOARTHRITISSURVEY}

Christian Bindesbø $\|^{1}$, Marco Garrido-Cumbrera ${ }^{2,3}$, Gunnstein Bakland ${ }^{4}$, Hanne Solveig Dagfinrud ${ }^{5}$,EMAS working group. ${ }^{1}$ Novartis Pharma AG, Norway, Oslo, Norway, ${ }^{2}$ Universidad de Sevilla, Health and Territory Research (HTR), Sevilla, Spain; ${ }^{3}$ Spanish Federation of Spondyloarthritis Associations (CEADE), Madrid, Spain; ${ }^{4}$ University Hospital of Northern Nonway, Department of Rheumatology, Tromsø, Norway, ${ }^{5}$ Diakonhjemmet Hospital, National Advisory Unit on Rehabilitation in Rheumatology, Oslo, Norway

Background: Obesity increases the risk of developing chronic inflammatory diseases, including axial spondyloarthritis $(\operatorname{axSpA})^{1,2}$. Information about how obesity correlates with disease activity in $\operatorname{axSpA}$ patients is limited.

Objectives: The objective of this survey was to investigate the association between body mass index (BMI) and patient reported disease activity in Norwegian axSpA patients.

Methods: The European Map of Axial Spondyloarthritis (EMAS), conducted from July 2017 to February 2018, was a cross-sectional on-line survey of 2,846 unselected patients with self-reported axSpA from 13 European countries (Austria, Belgium, France, Germany, Italy, Netherlands, Norway, Russia, Slovenia, Spain, Sweden, Switzerland, and the UK). Participants were recruited through an on-line panel and patient organizations. This analysis is based on data from the 509 Norwegian respondents. Sociodemographic variables (age, gender, BMI, comorbidity), and disease related variables (Bath Ankylosing Spondylitis Disease Activity Index (BASDAI) (0-10), self-reported spinal stiffness (3-12) and General Health Questionnaire (0-12) (GHQ-12)) were reported.

Results: Out of the 509 Norwegian participants with axSpA, 69.7\% (N:355) were women. The mean age was $48 \pm 12$ years, mean disease duration was $5.3 \pm 2.0$ years, $82.3 \%$ were HLA-B27 positive, and $55.2 \%$ (N:281) were university educated. In total, $35 \%(\mathrm{~N}: 180)$ of the participants were normal/underweight (BMI < 25) and 65\% (N:329) were overweight/obese (BMI >25). The mean (sd) disease activity, as measured by BASDAl (010), was 5.3 \pm 2.0 . Overweight/obese patients reported significantly higher disease activity (BASDAI 5.5 \pm 1.9 ) compared to normal weight patients (BASDAI 5.0 \pm 2.1). Moreover, being overweight/obese was associated with a significantly higher degree of spinal stiffness, number of comorbidities and a numerically, but not significantly, higher GHQ-12 score. There was no significant differences in alcohol consumption, smoking, or prevalence of inflammatory bowel disease (Crohn's disease or ulcerative colitis).

Conclusion: Norwegian overweight/obese axSpA patients from the EMAS survey report significantly higher disease activity, spinal stiffness and number of comorbidities. The results highlight the serious impact of overweight and obesity on the health status of axSpA patients. Therefore obesity should be considered as a preventable risk factor and within the disease management of axSpA

\section{REFERENCES}

[1] Maas, et al. Obesity Is Common in Axial Spondyloarthritis and Is Associated with Poor Clinical Outcome. The Journal of Rheumatology 2016; 43 (2) 383-387.

[2] Shan, et al. Impact of obesity on the efficacy of different biologic agents in inflammatory diseases: A systematic review and meta-analysis. Joint Bone Spine. 2018, in press.

Acknowledgement: EMAS was funded by Novartis Pharma AG Disclosure of Interests: Christian Bindesbøll Employee of: I currently work in Novartis Pharma AG Norway as listed in my affiliations, Marco Garrido-Cumbrera Consultant for: Honoraria from Novartis as steering committe of this survey, Gunnstein Bakland: None declared, Hanne Solveig Dagfinrud Consultant for: Honoraria from Novartis as a steering committee member on this survey

DOI: 10.1136/annrheumdis-2019-eular.7196

\begin{tabular}{|l|l}
\hline SAT0320 & FREQUENCY AND CHARACTERISTICS OF \\
INFLAMMATORY BOWEL DISEASE IN \\
SPONDYLOARTHRITIS WITH BIOLOGICAL THERAPY. \\
STUDY OF 270 PATIENTS FROM THE SAME CENTER
\end{tabular}

I. Calvo $^{1}$, O. Ibarguengoitia ${ }^{1}$, D M Montero $^{1}$, L Vega $^{1}$, L María $^{1}$, M E. Ruiz ${ }^{1}$, I Torre ${ }^{1}$, O Fernandez $^{1}$, J M. Blanco ${ }^{1}$, A R. Inchaurbe ${ }^{1}$, Clara Pérez ${ }^{1}$, Eduardo Cuende ${ }^{1}$, Natalia Rivera ${ }^{1}$, María Jesús Allande ${ }^{1}$, Helena Ugarte ${ }^{1}$, Iñigo Gorostiza ${ }^{2}$, E Galindez ${ }^{1} .{ }^{1}$ Basurto University Hospital, Rheumatology, Bilbao, Spain; ${ }^{2}$ Basurto University Hospital, Research Unit, Bilbao, Spain

Background: Inflammatory bowel disease (IBD) is an extra-articular manifestation that can appear in spondyloarthritis (SpA), as well as uveitis and psoriasis. Its prevalence is $5-10 \%$, although subclinical intestinal inflammation has been found in up to $60 \%$. Biological therapy (BT) can be the treatment for IBD or produce it paradoxically. Fecal calprotectin $(F C)$ is an intestinal inflammation marker, useful for early diagnosis and monitoring disease activity.

Objectives: To describe the frequency and characteristics of IBD in SpA with BT.

Methods: Descriptive and retrospective study (January 2003-January 2019) of patients with SpA that develop IBD in a single center. Epidemiological variables, type of $\mathrm{SpA}$, presence of $\mathrm{IBD}$ and its characteristics, levels of $\mathrm{FC}$, presence of $\mathrm{BT}$ at IBD onset and treatment received were registered. For the analysis, frequencies and percentages were used in qualitative variables and mean \pm standard deviation (SD) in quantitative. Statistical analysis was performed with IBM SPSS v.23.

Results: We studied 270 patients with SpA, 70.4\% male with a mean age of $39.9 \pm 12$ years. The subtypes of $\mathrm{SpA}$ were: ankylosing spondylitis (AS) $(n=133 ; 49.3 \%)$, psoriatic arthritis (PsA) ( $n=116 ; 43 \%)$, undifferentiated $\operatorname{SpA}(\mathrm{n}=16 ; 5.9 \%)$, SpA non- $\mathrm{Rx}$ axial $(\mathrm{n}=3 ; 1.1 \%)$ and reactive arthritis $(n=2 ; 0.7 \%)$

IBD was observed in 25 patients $(9.26 \%), 80 \%$ male. At the time of IBD onset, they had a mean age of $39.12 \pm 9.8$ years, the mean ESR was $31.15 \pm 24 \mathrm{~mm} 1^{\mathrm{a}} \mathrm{h}, \mathrm{CRP} 2.7 \pm 2 \mathrm{mg} / \mathrm{dL}$ and BASDAl 4.6. 16 patients had AS, 6 PsA and 3 undifferentiated SpA. TABLE 1.

Regarding Spa diagnosis, IBD appeared after in 15 patients with an average time of development of $8.39 \pm 8$ years, before in 7 and was simultaneous in 3 . The subtypes of IBD were: Crohn's disease (CD) in 13 patients, ulcerative colitis (UC) in 9 and indeterminate colitis (IC) in 3 The FC was $>200 \mu \mathrm{g} / \mathrm{g}$ in 17 patients $(68 \%)$, normal $(<50 \mu \mathrm{g} / \mathrm{g})$ in 1 and between $50-200 \mu \mathrm{g} / \mathrm{g}$ in 7 . The incidence rate adjusted for follow-up of the 25 cases was 7.7 cases/1000 patients-year.

At the time of the IBD onset, 6 patients were with BT: Etanercept (ETN) $(n=2)$, Infliximab (IFX) $(n=1)$, Adalimumab (ADA) $(n=1)$, Secukinumab (SCK) $(n=1)$ and Ustekinumab (UST) $(n=1)$. The BT had been initiated the previous 12 months in 5 of them. The incidence rate adjusted for follow-up of the 6 cases of IBD after BT was 1.83 cases/1000 patient-years. TABLE 2. The treatment of the 25 patients with IBD was mesalazine $(n=15)$, oral corticoid $(n=5)$, methotrexate $(n=7)$ and BT in all cases. The BT was: 